\title{
Versatility of soil column experiments to study biodegradation of halogenated compounds under environmental conditions
}

Jan Roelof van der Meer, ' Tom N.P. Bosma, Wil P. de Bruin, Hauke Harms, Christof Holliger, ${ }^{2}$ Huub H.M. Rijnaarts, Marijke E. Tros, Gosse Schraa \& Alexander J.B. Zehnder ${ }^{1}$ Department of Microbiology, Wageningen Agricultural University, Hesselink van Suchtelenweg 4, 6703 CT Wageningen, The Netherlands (present addresses: ' EAWAGIETH, CH-8600 Dübendorf \& ${ }^{2}$ EAWAGIETH, CH-6047 Kastanienbaum, Switzerland)

Key words: xenobiotic compounds, chlorobenzenes, tetrachloroethylene, reductive dehalogenation, residual concentration, desorption, genetic adaptation, Pseudomonas sp. strain P51, adhesion properties

\section{Abstract}

Soil column experiments were performed to obtain insight in the different biological and physico-chemical processes affecting biodegradation of halogenated compounds under natural conditions in a water infiltration site. Lower chlorinated aromatic compounds could be degraded under aerobic conditions, whereas highly chlorinated compounds and chlorinated aliphatic compounds were mainly transformed under anaerobic conditions. Microorganisms which derive energy from reductive dechlorination were enriched and characterized. It was found that microbes could adapt to using chlorinated benzenes by evolution of new enzyme specificities and by exchange of genetic material. For halogenated pollutants, which are generally hydrophobic, sorption processes control the concentration available for biodegradation. The effects of very low concentrations of halogenated compounds on their biodegradability are described. The use of isolated bacterial strains to enhance biodegradation was evaluated with respect to their temperature-related activity and to their adhesion properties.

Abbreviations: 3-CB - 3-chlorobenzoate, DCB - dichlorobenzene, HCH - hexachlorocyclohexane, IS insertion sequence, $P E R$ - tetrachloroethylene, $S_{\min }$ - minimal substrate concentration for growth, TCB trichlorobenzene, TRI - trichloroethylene, $\lambda$ - filtration coefficient

Introduction

The widespread use of halogenated organic compounds for more than fifty years, has raised consid. erable concern about their persistence in the environment (Alexander 1985). These compounds are applied as solvents, pesticides, intermediates, or preservatives in industry, agriculture, or households (Pearson 1982). As a result, halogenated compounds can be found almost in any natural habitat. For instance, tetrachloroethylene, trichlo- roethylene, methylenechloride, or 1,2-dichlorobenzene, are used as solvents in dry cleaning and degreasing of electronic or metal parts, and enter the natural environment through spills, evaporation, or via wastewater discharges. Pesticides are usually directly introduced into the environment of their purpose, and in the case of lindane or DDT can end up in higher organisms via food webs. An important route via which halogenated compounds find their way to the groundwater is leaching from waste disposal sites. Higher chlorinated com- 
pounds can be formed during the incineration of domestic waste and be spread via the atmosphere (Pearson 1982).

Halogenated compounds are generally considered as being xenobjotic, i.e. foreign to existing life forms. This terminology refers to their uncommon chemical structures, or presence of uncommon side groups or atoms (such as halogens) on the molecules, which renders them more difficult for enzymatic attack. Xenobiotic compounds or their metabolites are often toxic to the biological world and may therefore persist in the environment for long times. Not all halogenated compounds, however, are to be considered 'xenobiotics', since more than 200 halogenated compounds are known to be produced by bacteria, algae and sponges (Faulkner 1980).

The fate of xenobiotic substances in the environment is governed by degradation processes among which biodegradation and by their distribution in the different environmental compartments, soil, water and air. The distribution is determined by physico-chemical properties such as hydrophobicity, solubility, or volatility. The distribution parameters influence largely the concentration of the compounds in the water phase and thus their mobility and transport, either solubilized or particlebound, and their accessibility for biodegradation. Microorganisms can play an important role in the degradation of halogenated organic compounds. However, the persistence and accumulation of halogenated compounds in cerain environmental compartments indicate their recalcitrance to biodegradation. The possibilities for biodegradation are dependent on the metabolic potential of the microorganisms and on pilysico-chemical factors which determine microbial activity in the environment, such as physical (temperature, water potential, accessibility of the substrate), chemical ( $\mathrm{pH}$, redox state, concentration of the compounds, pres. ence of additional secondary substrates, salinity), and biological conditions (presence of 'predators, adsorption of microbes to surfaces) (Goldstein et al. 1985; Klein \& Alexander 1986; Swindoll et al. 1988). Together all these factors determine whether or not a halogenated compound will disappear readily from the environment, or will persist and inflict long-term damage on the quality of our eavironment.

\section{Aim of this research}

Groundwater is an important source for drinking water in The Netherlands. In beavily populated areas the amount of groundwater is not sufficient to cover all needs, and surface waters are used as source for drinking water, either directly, or after infiltration into the soil. The quality of both groundwater and of surface water, such as river water, is increasingly threathened by the presence of organic micropollutants. Pesticide residues, vent spills, or wastewater discharges account for the pollution of ground- and surface water, and cause the quality decline of this important resource. Increasing efforts are needed to purify the water before it can be used as drinking water.

To investigate the fate of organic compounds during infiltration of river water into the soil, collaborate projects were started between our laboratory and the Amsterdam Water Works in 1984. Soil column experiments were set up to mimic the infiltration conditions of water into the soil, and to study transport, distribution, and biodegradability of a defined set of mainly halogenated compounds (Fig. 1). These served as model compounds for the great variety of micropollutants in river water (Bosma et al. 1991; Bosma et al., in preparation). In this article an overview is given of a number of our studies which address various aspects of biodegradation in a soil-water system. The topics include, (i) the possibilities for biodegradation of organohalogen compounds under different redox conditions, (ii) biodegradation at very low substrate concentrations and the effect of adsorption and desorption on the biodegradability, (iii) the metabolic potential of the microorganisms present in the natural environment and the capacity to adapt to xenobiotic substrates, and (iv) the use of purified or enriched strains to enhance biodegradation in soil-type reactors. In. this last part special emphasis is given to the temperature-related activity of microorganisms and the adhesion properties. The adhesion properties are important because they 


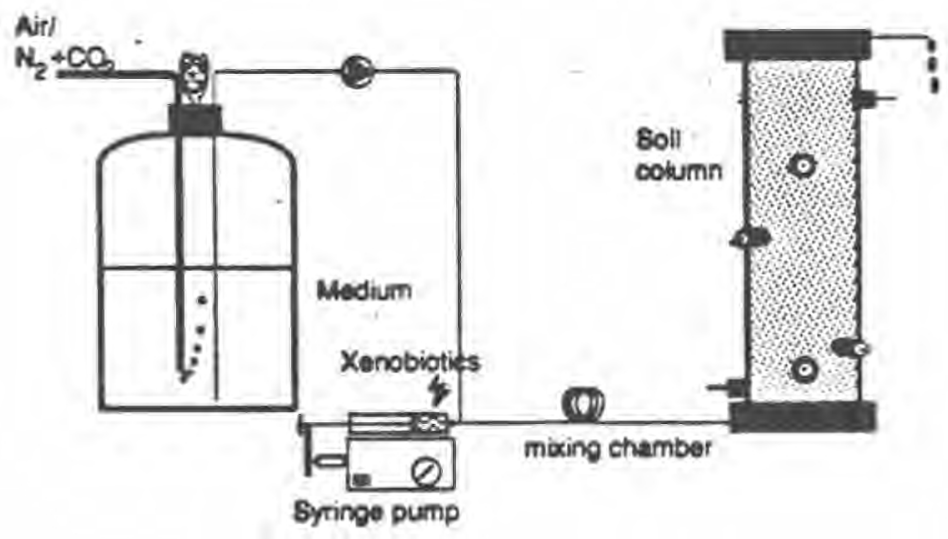

Fig. 1. The soil column system used in the different studies. A mineral medium, which can be aerated or purged with $\mathrm{N}_{2} / \mathrm{CO}_{2}$ diring anaerobic studies, is pumped through water-saturated soil column. Xenobiotic compounds are added to the mineral medium via a syringe pump, which allows accurate dosing. Stainless steel tubes at various positions pointing into the middle of the column are used to ample the liquid phase.

determine whether introduced microorganisms are retained or transported through the porous medium.

Biodegradation of organohalogen compounds under different redox conditions

Perhaps most information exists on the possibilities for degradation of halogenated compounds under different redox conditions. Many halogenated aromatic compounds can be degraded under aerobic conditions by microorganisms which either use these compounds as growth and energy source or co-metabolize them. The different pathways and reactions that microorganisms use to attack and metabolize halogenated compounds have been reviewed extensively (Chaudry \& Chapalamadugu 1991; Commandeur \& Parsons 1990; Haggblom 1990; Neilson 1990; Reineke \& Knackmuss 1988). Of the halogenated aromatic compounds, the lower chlorinated aromatics are degraded generally more readily than higher chlorinated ones. Aerobic microorganisms can also degrade halogenated aliphatic compounds, such as haloalkanes and haloacids. Higher chlorinated aliphatic compounds (e.g. tetrachloroethylene) still remain problematic. The main mechanisms by which aerobic microorganisms remove halogen atoms include sub. stiturion (e.g. by the hydroxyl ion $\mathrm{OH}$, a reaction catalyzed by hydroxylases), oxidation (the incorporation of oxygen, catalyzed by mono- and dioxygenases), or fortuitously (e.g. during lactonization of chloromuconic acid) (Chaudry \& Chapalamadugu 1991; Commandeur \& Parsons 1990; Haggblom 1990; Neilson 1990; Reineke \& Knackmuss 1988). Less is known about the conversion reactions that can take place with halogenated compounds under anaerobic conditions (i.e. denitrifying, sulfate-reducing, or methanogenic), and the specific microorganisms which are involved in these reactions. The main mechanism which has been described is the reductive dehalogenation (Suflita et al. 1982), which includes processes like hydrogenolysis, hydrolytic reduction, or dihalo-elimination (Holliger 1992).

We used soil columns, illed with sediment of the river Rhine or of the Dune infiltration area near Amsterdam in The Netherlands to study the possibilities for biodegradation of halogenated compounds under different redox conditions (Bosma et al., in preparation). The columns were percolated under water-saturated conditions with a mineral medium to which very low concentrations of different chlorinated compounds could be added (Fig. 1). Parallel experiments were performed in the laboratory of the Amsterdam Water Works, which made use of larger soil columns and a wider range of different organic micropollutants. The com- 


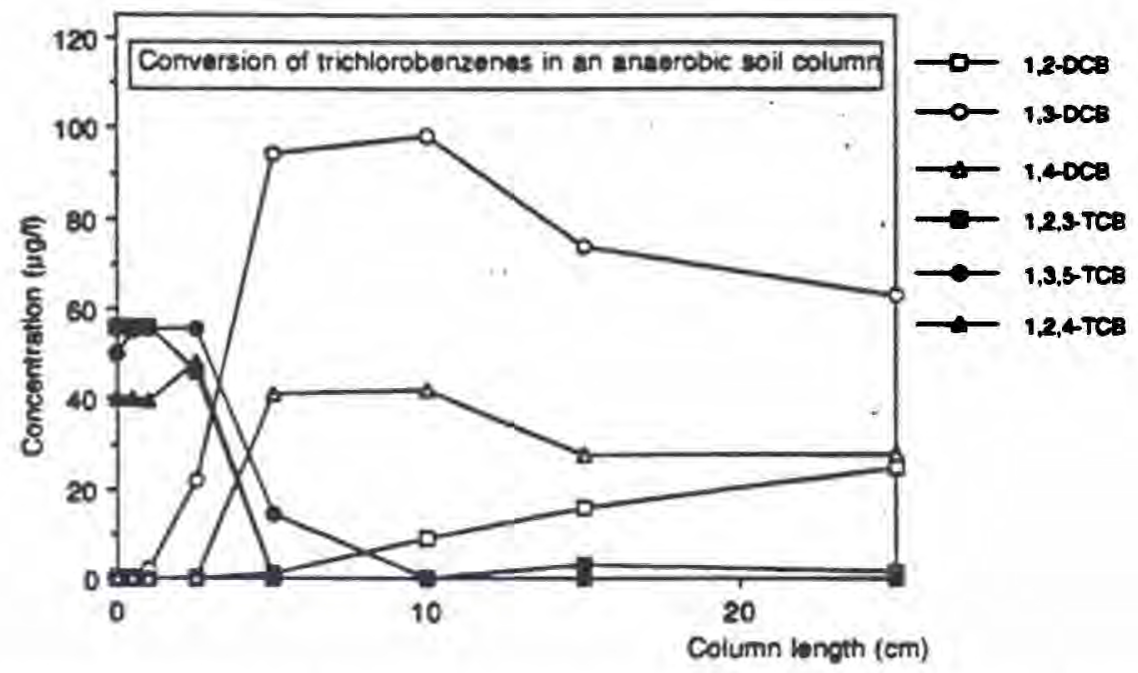

Fig. 2. Conversion of trichlorobenzenes in an anaerobic soil column after 300 days of continuous operation. Profile measurements of chlorobenzene concentrations along the length of the column show the disappearance of trichlorobenzene isomers and the formation of dichlorobenzene isomers. Figure redrawn from Bosma et al. (1988c).

pounds which were tested in these systems included chlorinated benzenes, non-chlorinated aromatics (benzene, toluene, naphthalene, di- and trimethyl-

Table 1. Observed degradation of halogenated compounds in Rhine and Dune sediments under different redox conditions.

\begin{tabular}{|c|c|c|}
\hline \multirow[t]{2}{*}{ Compound } & \multicolumn{2}{|c|}{ Degradation } \\
\hline & Aerobic & Sulfate reducing \\
\hline Benzene & ++ & - \\
\hline Monochlorobenzene & ++ & - \\
\hline 1,2-dichlorobenzene & + & + \\
\hline 1,3-dichlorobenzene & $+1-$ & + \\
\hline 1,4-dichlorobenzene & + & + \\
\hline 1,2,3-trichlorobenzene & - & ++ \\
\hline 1,2,4-trichlorobenzene & + & $+t$ \\
\hline 1,3,5-trichlorobenzene & - & + \\
\hline 1,2,3,4-tetrachiorobenzene & - & ++ \\
\hline 1,2,4,5-tetrachlorobenzene & + & + \\
\hline Peatachlorobenzene & - & ++ \\
\hline Hexachlorobenzene & - & ++ \\
\hline Tetrachloroethylene & - & ++ \\
\hline Trichloroethylene & - & ++ \\
\hline Chloroform & - & ++ \\
\hline
\end{tabular}

-; no removal observed.

$+1-$ : removal less than $25 \%$.

+t: removal berween $25 \%$ and $90 \%$.

++ : removal more than $90 \%$. benzenes), volatile chlorinated aliphatic compounds (chloroform, trichloroethylene, tetrachloroethylene, hexachloro-1,3-butadiene), and a number of pesticides (atrazine, bentazon). Our results (Table 1) showed that under aerobic conditions mainly transformations of lower chlorinated aromatic compounds are observed, such as dichlorobenzenes, 1,2,4-trichlorobenzene, or 2-chlorotoluene (not shown). All non-chlorinated aromatic compounds disappeared rapidly from the soil columns to undetectable levels. Under anaerobic (sulfate-reducing) conditions most of the higher chlorinated benzenes (Bosma et al. 1991; Bosma et al., in preparation; Bosma et al. 1988c) and most of the halogenated aliphatic compounds were transformed. In the dune infiltration areas and in most soils, both aerobic/anaerobic conditions may exist, thus promoting sequential transformation reactions which could favour a complete transforma. tion of the higher chlorinated compounds. Two transformation processes were studied in greater detail and will be discussed further in this section, (i) anaerobic conversions of higher chlorinated benzenes, and (ii) anaerobic conversions of tetrachloroethylene.

Biodegradation of trichlorobenzene (TCB) isomers (1,2,4-TCB, 1,2,3-TCB, and 1,3,5-TCB) 

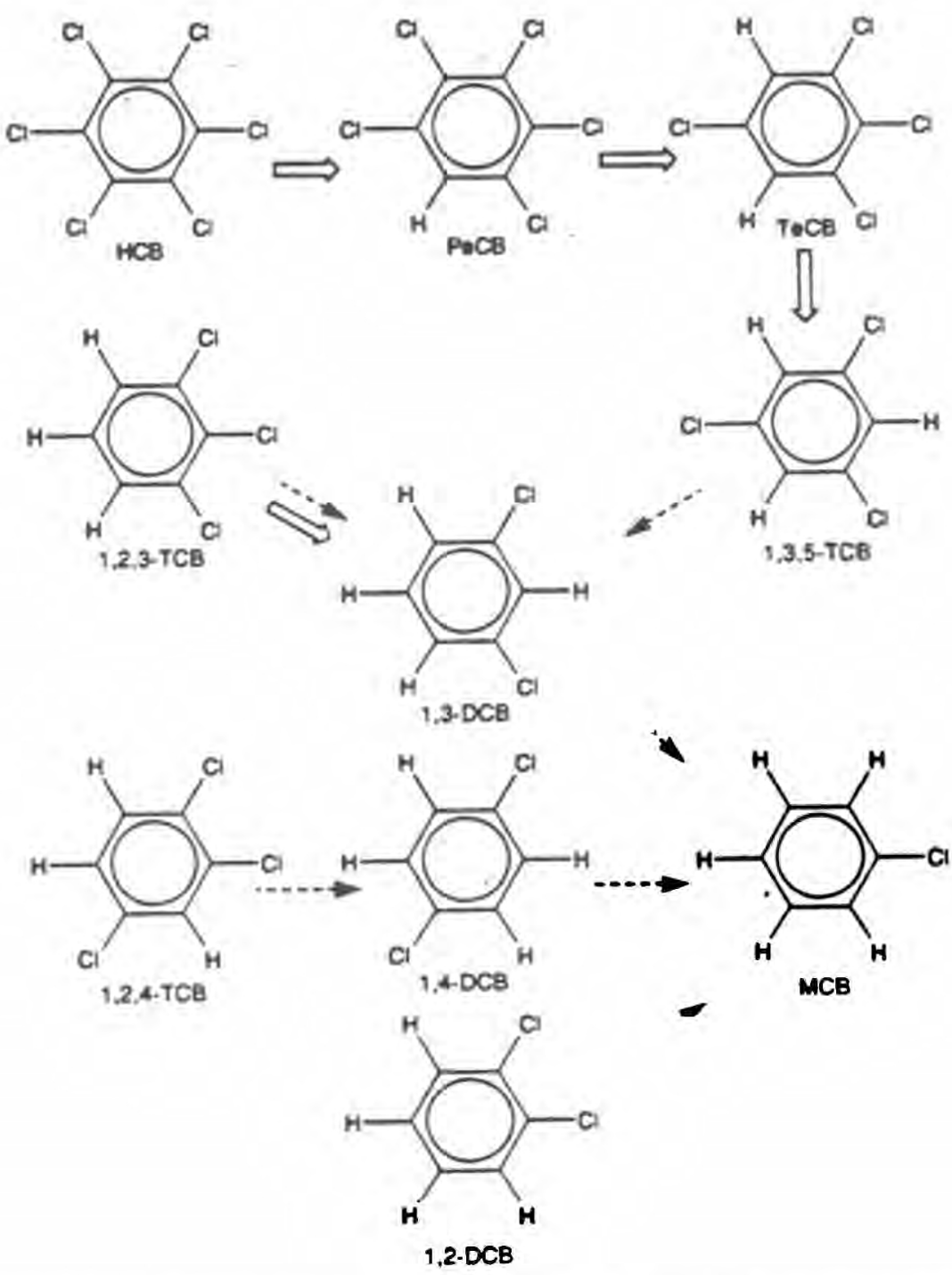

Fig. 3. Reatative dechlorination of highly chlorinated benzenes to monochlorobenzene, as observed in anaerobic soil columns (dotted arrows). and by a mixed culture which was ennched for reductive dechlorination of 1,2.3-TCB to 1,3-DCB (open arrows). Abbreviations: HCB, hexachlorobenzene: PeCB, pentachlorobenzene; TeCB, 1,2,3,5-tetrachlorobenzene; TCB, trichlorobenzene; DCB. dichlorobenzene; MCB, monochlorobenzene. Figure redrawn from Bosma et al. (1988c) and Holliger et al. (1992).

was studied in an anaerobic soil column for more than $\mathbf{4 5 0}$ days of continuous operation (Bosma et al. 1988c). During this period we detected transformations of all TCB-isomers in the column and a concomitant appearance of dichlorobenzenes (DCB) (Fig. 2). Applying one of each TCB-isomer at the time to this column revealed that the TCBs were transformed to a corresponding DCB by stepwise removal of one chlorine atom, suggesting a process of reductive dechlorination (Fig. 3). The DCB-isomers on their turn were transformed to monochlorobenzene, which was not further dechlorinated in the column. Subsequently, enrichments were started with material from this soil column to isolate microorganisms responsible for these conversion reactions. This resulted in an anaerobic mixed culture which could reductively dechlorinate 1,2,3-TCB to 1,3-DCB (Holliger et al. 


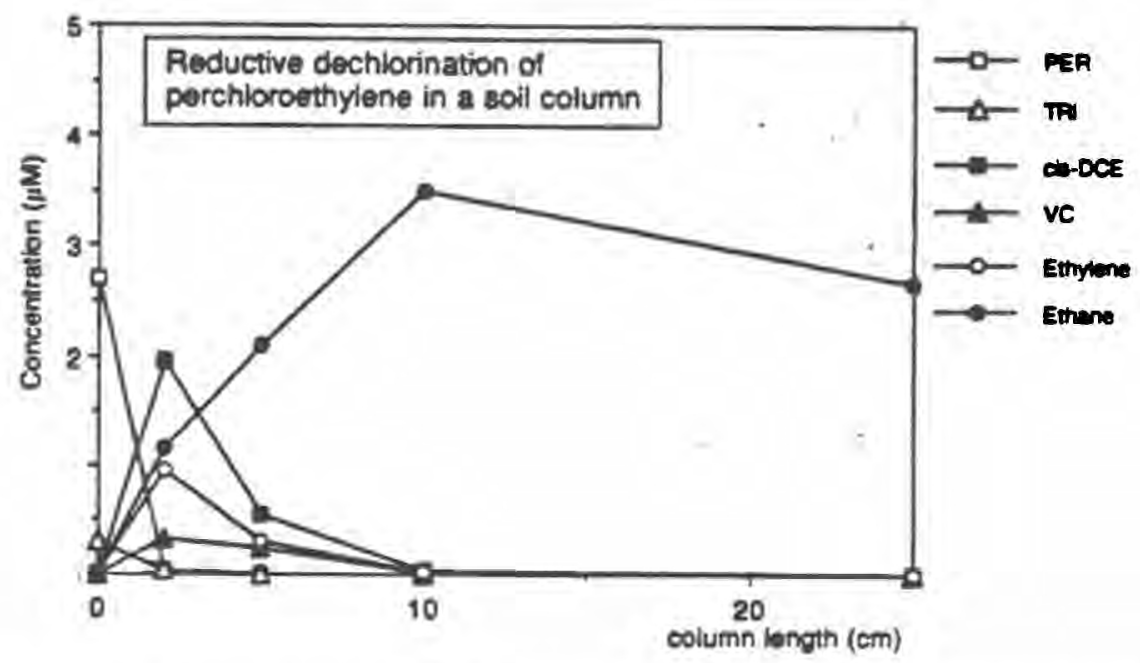

Fig. 4. Transformation reactions of tetrachloroethylene (PER) in an anaerobic soil column, indicating successive steps of dechlorination to trichloroethylene (TRI), cis-dichloroethylene (cis-DCE), vinylehloride (VC), ethylene and ethane.

1992). This mixed culture was also able to stepwise dechlorinate hexachlorobenzene, pentachlorobenzene and 1,2,3,5-tetrachlorobenzene to 1,3,5-TCB (Fig. 3). The dechlorinating activity in the mixed culture was most likely not caused by sulfate-reducing or methanogenic organisms, but appeared to be a specific reaction of bacteria which used 1,2,3TCB as terminal electron acceptor and $\mathrm{H}_{2}$ as electron donor. Interestingly, the mixed culture was not able to dechlorinate $1,3,5-$ TCB or $1,2,4-$ TCB which were being transformed in the original soil column (Bosma et al. 1988c; Holliger 1992). This indicated that in the original soil column other microorganisms must have been present with other specific dechlorinating activities.

In similar soil columns operated under sulfatereducing conditions we detected transformation of tetrachloroethylene (PER) and trichloroethylene (TRI), resulting in a stoichiometric formation of cis-1,2-dichloroethylene (Bosma et al. 1988a). Subsequent studies in a packed-bed column which was filled with anaerobic granular sludge and sediment of the river Rhine near Wageningen, NL, clearly showed complete step-wise reductive dechlorination of PER to TRI, cis-dichloroethylene, vinylchloride, ethylene, and finally even to ethane (Figs. 4 and 5) (de Bruin et al. 1992). A coculture was enriched from this soil-slurry column by using a two-liquid-phase system which could dechlorinate PER and TRI (Holliger 1992). This enrichment was able to derive energy from the dechlorination of PER or TRI, used as electron acceptor, and $\mathrm{H}_{2}$ or formate as electron donor. The reduction of PER to cis-1,2-dichloroethylene yields $377 \mathrm{~kJ}$, which is by far more energy than can be obtained from sulfate reduction or methanogenesis (Holliger 1992). This raises the intriguing hypothesis that microorganisms in this enrichment found a new ecological niche by exploiting the energy content of a very specific xenobiotic compound.

\section{Biodegradation at very low substrate concentrations

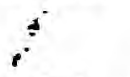

The actual concentrations of halogenated pollutants in the natural environment are mostly in the range of $\mathrm{nM}$ to $\mu \mathrm{M}$. Although the compounds may be present in much higher amounts in the bulk, the concentration in the water phase is often rather low. These extremely low concentrations are due to the poor water solubility of most balogenated compounds, and/or their sorption to a solid phase, either to colloid particles (as in surface waters), or to the soil matrix or soil organic phase. The sorption behaviour of halogenated compounds to the 
organic phase in soils and sediments can be described by using empirical equations which are based on the octanol-water partition coefficients of the compounds (Schwarzenbach \& Westall 1981). Lowering of the dissolved concentration as a result of sorption to a solid matrix can be beneficial in the case of toxic compounds, or it can prevent or limit biodegradation because of too low concentrations in the water phase (Rijnaarts et al. 1990). Sorption to the solid matrix initially acts as an effective sink for many hydrophobic compounds. However, the sorbed material may be released very slowly and can steadily pollute the environment for very long periods of time.

The effects of desorption rates on biodegrada. tion were shown in studies performed in our laboratory with a-hexachlorocyclohexane ( $\mathrm{HCH})$. Biodegradation of a-HCH under aerobic conditions can proceed rapidly (Bachmann et al. 1988; Huntjens et al. 1988). However, soil samples contaminated with $\mathrm{HCH}$-isomers taken from a wastedisposal site in The Netherlands, which were incubated as soil-slurries in end-over-end mixing systems, showed a much lower biodegradation rate (Rijnaarts et al. 1990). This could be attributed to the desorption kinetics of $\mathrm{HCH}$ from the soil matrix, which in this case was rate-limiting for bioconversion. Breakage of the soil aggregates by vigorous stirring, resulting in smaller average size of the soil particles, increased drastically the observed biodegradation rates, since more adsorbed $\mathrm{HCH}$ was exposed to the bulk liquid phase.

To determine whether very low concentrations of halogenated compounds can still be degraded by microorganisms or whether certain thresholit levels exist for biodegradation (Alexander 1985), experiments were initiated to investigate the kinetics of substrate removal at very low concentrations in the $\mathrm{nM}$ to $\mu \mathrm{M}$ range. Inoculation into soil columns of a pure culture of Pseudomonas sp. strain P51, an organism able to use DCBs and 1,2,4-TCB as the sole carbon and energy sources (see below), exhibited a residual concentration for 1,2-DCB of approximately $67 \mathrm{nM}$, and for 1,2,4-TCB of $108 \mathrm{nM}$ (van der Meer et al. 1987). At the flow rates operated in these columins $(10.6 \mathrm{~mL} / \mathrm{h}$ : concentrations of $1,2-\mathrm{DCB}$ in the range of $134 \mathrm{nM}$ to $6.7 \mu \mathrm{M})$, this

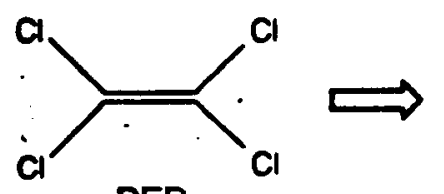

PER

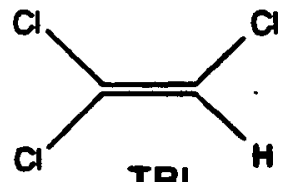

TRI
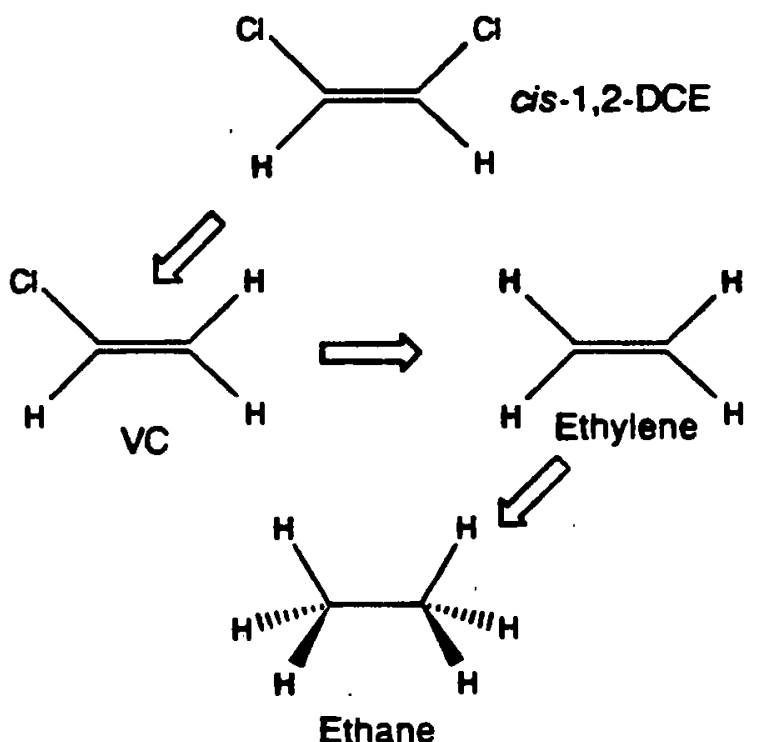

Fig. 5. Reductive dechlorination steps of tetrachloroethylene to ethane (see legends to Fig. 4). The transformation of PER to TRI and cis-1,2-DCE is carried out by the coculture described in the main text. which can derive energy from PER or TRI as sole electron acceptor and $\mathrm{H}_{2}$ or formate as electron donor.

residual concentration could not be lowered. Incubation of the column effluent containing similarly low 1,2-DCB concentrations with Pseudomonas sp. strain P51 in batch experiments, resulted in a disappearance of $1,2-\mathrm{DCB}$ to a value below the detection limit of $0.6 \mathrm{nM}$ (van der Meer et al. 1987). Further experiments to study the nature of threshold levels were performed with Pseudomonas sp. strain B13 (Tros, unpublished). Hereto resting cell suspensions were prepared by growing the cells on 3-chlorobenzoate (3CB), washing them several times in buffered media without $3 \mathrm{CB}$, and then starving them for substrate for about $20 \mathrm{~h}$. Addition of $\left[{ }^{14} \mathrm{C}\right]$-labeled acetate or $\left[{ }^{14} \mathrm{C}\right]-3 \mathrm{CB}$ to these cell suspensions caused uptake of the compounds resulting in a residual concentration which was be- 
low the detection limits, independent of the amount of substrate added (in a range of $10 \mathrm{nM}$ to $1500 \mathrm{nM}$ for $3 C B$, and $80 \mathrm{~nm}$ to $8000 \mathrm{nM}$ for acetate). This indicated that no measurable threshold levels exist in batch incubations (Fig. 6A). In contrast, when strain B13 was cultivated in a recycling fermentor, residual concentrations were detected again (Fig. 6B). The use of a recycling fermentor enables the study of microbial growth at very low substrate concentrations (Pin 1975). The biomass is completely retained in the fermentor (Fig. 6B), and a constant supply of fresh substrate in the medium results in growth of the biomass to a certain limit. Several phases can be observed from the stant of a fermentation cycle (Fig. 6B), an exponential growth phase (I), two linear phases (II and III), in which the substrate addition becomes growth rate-limiting and the growth of biomass ( $d X / d t)$ becomes constant (Chesbro et al. 1979), and finally a phase (IV) where the substrate flow can only compensate the maintenance energy of the existing biomass, and growth becomes zero. In this phase a minimal substrate concentration $\left(S_{\text {min }}\right)$ can be de. termined, which depends on the growth parameters of the specific strain on that particular substrate ( $\mu_{\text {orex }}, K_{s}$, and maintenance rate (b)) (Chesbro et al. 1979). Using growth kinetic parameters which were independently derived for strain B13 on $3 C B$ (Tros, unpublished) we could calculate an $S_{\min }$ of $8 \mu \mathrm{M}$ at $20^{\circ} \mathrm{C}$, and $11 \mu \mathrm{M}$ at $30^{\circ} \mathrm{C}$ (see the equation of Fig. 6) (Pirt 1975). This value was in good agreement with the residual concentration of $10 \mu \mathrm{M}$ observed in the recycling fermentor in phase IV (Fig. 6), suggesting that this residua'd concentration indicates a minimal substrate concentration for growth of Pseudomonas sp. strain B13 on 3-CB. These results showed that in a static system, such as a batch culture, a complete degradation of substrates is possible to unmeasurable low concentrations (<0.5 $\mathrm{nM}$ for 3-CB). However, in dynamic systems, such as a fermentor, a soil column, reactor, or perhaps the soil/water interphase, a residual concentration may occur, reflecting a minimal substrate concentration which depends on the growth kinetic parameters of bacterial strains with that specific metabolic substrate. Interestingly, we found no threshold levels for 1,2-DCB in naturally adapted soil columns (van der Meer et al. 1987), indicating that indigenous microorganisms may be present in the soil with different growth kinetic parameters, and perhaps specialized in low substrate level conversions.

\section{Adaptation of microorganisms to xenobiotic compounds}

Microorganisms are important for the breakdown of many halogenated compounds in the environment. However, since many of the chlorinated compounds have uncommon structures, the majority of the microorganisms present in the natural environment may not be able to deal effectively with these compounds, even if the environmental conditions are favourable (see above). The strong efforts of microbiologists in the last decades have resulted in the isolation of many new bacterial species, which are able to use a large variety of previously considered recalcitrant compounds as growth and energy substrates, such as chlorinated benzenes (Sander et al. 1991; Schraa et al. 1986; Spain \& Nishino 1987; van der Meer et al. 1987; van der Meer et al. 1991b), chlorinated biphenyls (Furukawa et al. 1978; Mondello 1989), halogen-containing pesticides (Don \& Pemberton 1981; Karns et al. 1983), or chloroanilines (Zeyer et al. 1985), suggesting that microbes adapted to xenobiotic compounds. However, this does not tell us what the catabolic potential of the indigenous microbes is, and if adaptation can occur under environmental conditions to compounds which were not previously recognized as metabolizable substrates. Adaptation may result from an induction of existing enzyme systems in microorganisms upon addition of a substrate, which may then be followed by growth of this sub-population of microorganisms owing to their activity on this substrate (Barkay \& Pritchard 1988). Such an adaptation has been observed for growth on p-nitrophenol (Aelion et al. 1987). In the case of less easily degradable substrates such as chlorinated benzenes, adaptation may require genetic changes in the microorganisms or exchange of genetic material between different microorganisms before the suitable metabolic pathways arise (van 


\section{A. Batch experiment}
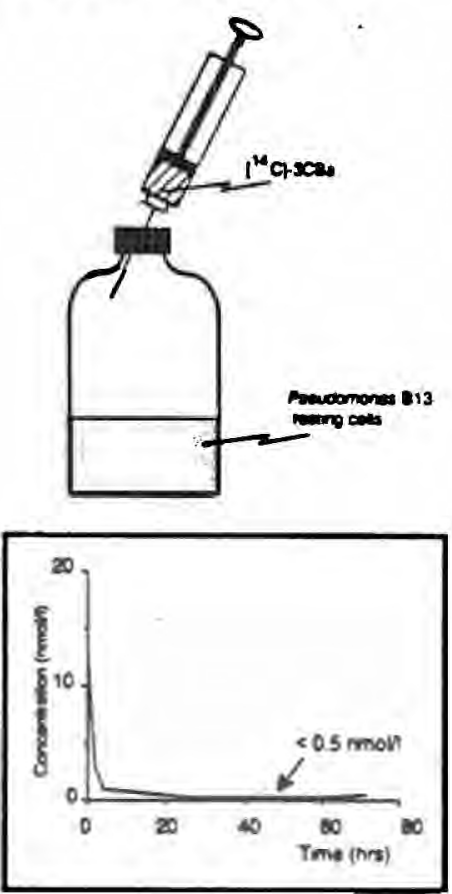

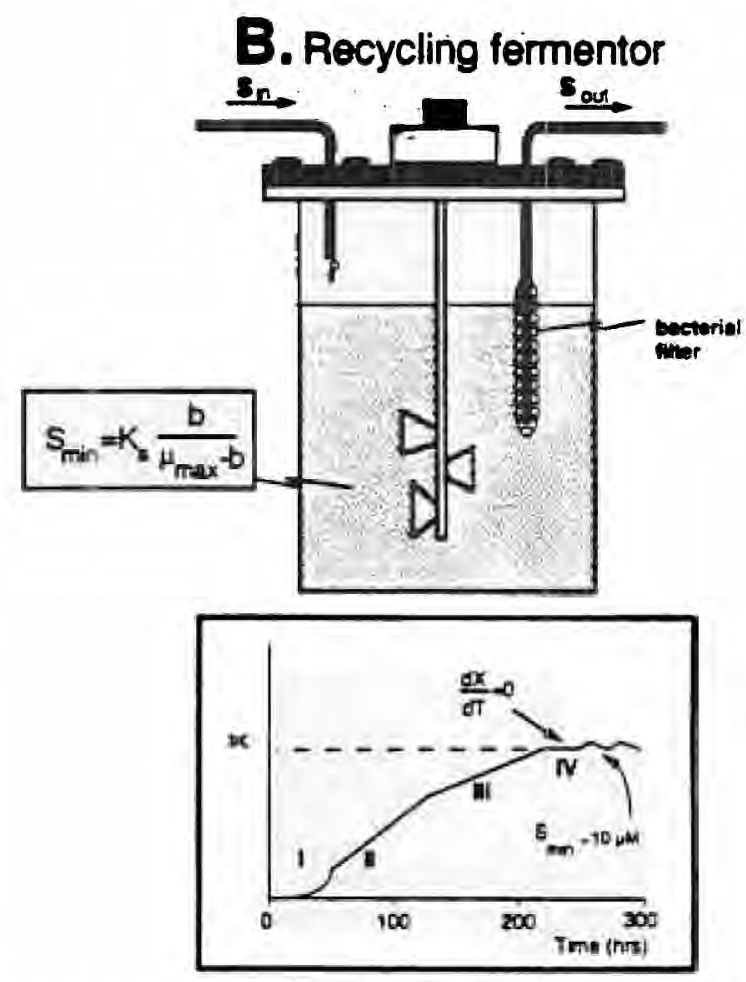

Fig. 6. Experimental set-up to detect the presence of threshold levels for microbial growth and activity. A). Batch experiments with resting cells of Pseudomonas sp. strain B13 to which [ $\left.{ }^{14} \mathrm{C}\right]-3$-chlorobenzoate (3CB) was added. Time measurements of the uptake of $3 \mathrm{CB}$ and the remaining concentration indicated that no threshold level can be detected (lower panel). B). The recycling fermentor which was used to study growth of strain B13 at very low substrate concentrations. A bacterial filter prevents outflow of the biomass. The biomass concentration in the fermentor as a function of time behaves schematically as drawn in the lower panel. For an explanation of the different phases. see the main text. In phase IV, the net growth of the biomass is zero, and in this phase the minimal substrate concentration $\left(S_{\min }\right)$ can be measured. $S_{\min }$ can be calculated as a function of growth kinetic parameters $\left(K_{\text {, and }} \mu_{\text {mex }}\right)$, and of the maintenance rate, b (Chesbro et al. 1979; Pin 1975).

der Meer et al. 1991c). Several genetic mechanisms may play a role in genetic adaptation, such as mutation, slippage-repair, recombination and transposition, or gene transfer (van der Meer et al. 1992). Here we will describe the adaptation to chlorinated benzenes in soil columns and the possible genetic changes which may have taken place upon adaptation to chlorinated benzenes in Pseudomonas sp. strain P51.

Only fairly recently microorganisms were isolated which were able to degrade chlorinated benzenes. The first such strain which could metabolize monochlorobenzene was obtained by Reineke \& Knackmuss by using a chemostat for enrichment (Reineke \& Knackmuss 1984). Several other strains were since then isolated, and the metabolic pathway for chlorobenzene degradation was largely unraveled (Sander et al. 1991; Schraa et al. 1986; Spain \& Nishino 1987; van der Meer tt al. 1991b). Aerobic metabolism of chlorinated benzenes proceeds similarly as that of other aromatic compounds, such as toluene, benzene, benzoate, or naphthalene. The initial attack of the aromatic ring is performed by an aromatic ring dioxygenase, a multi-enzyme complex which incorporates oxygen into the ring (Fig. 7). This intermediate is subsequently converted to a (chlorosubstituted) catechol, which is of a class of dihydroxylated com: pounds that are central intermediates in most aerobic aromatic pathways. Further ring-cleavage of the catecholic intermediates in bacteria is catalyzed by a class of enzymes, performing either intradiol 


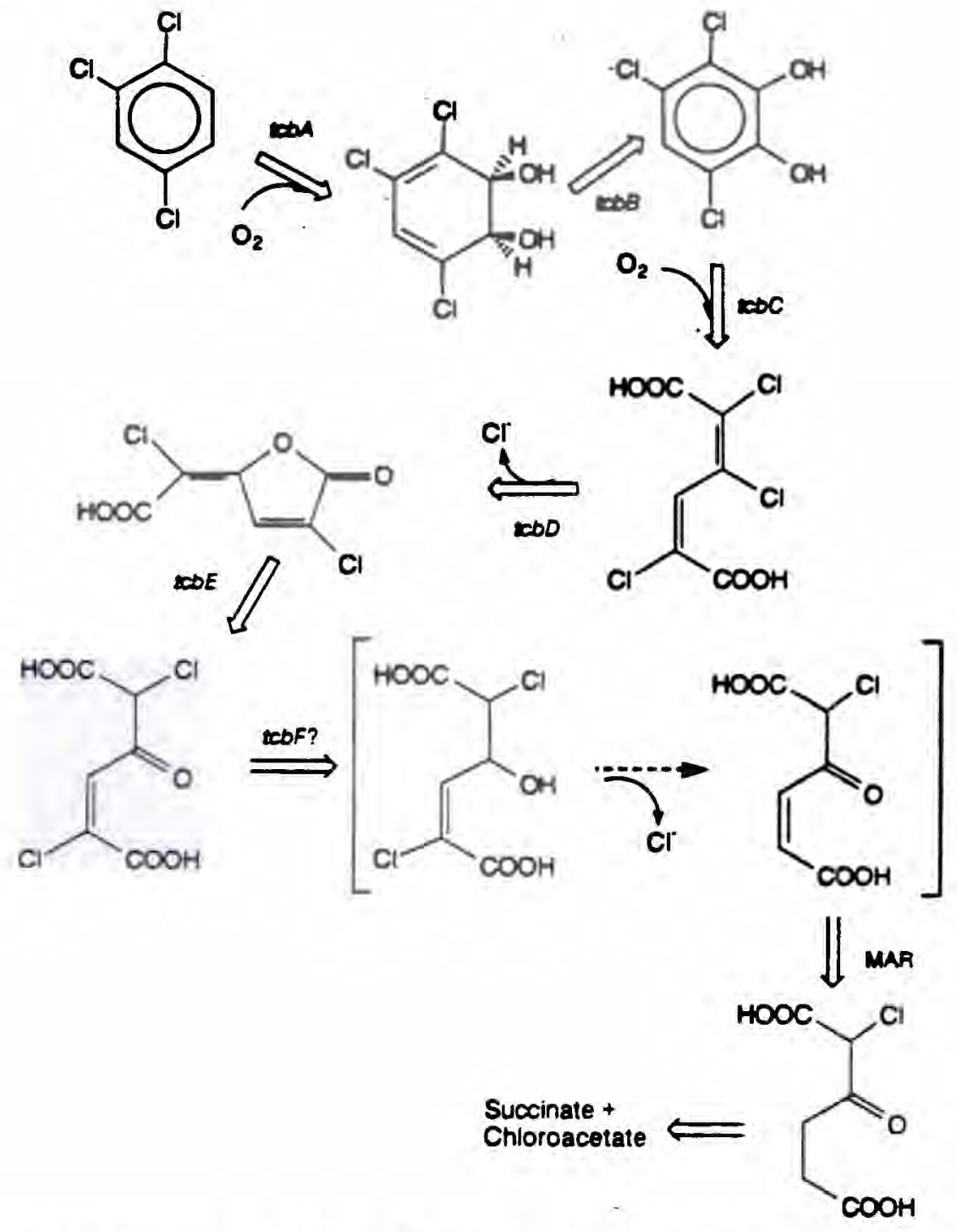

Fig. 7. Metabolic pathway of 1.2,4-trichlorobenzene in aerobic microorganisms proceeds via an aromatic ring dioxygenase, dehyd-ogecase, and a modified ortho cleavage pathway (Sander et al. 1991; van der Meer et al. 1991b). Two chloride atoms are relea-ed fortuitously during the conversion steps. The last part of the pathway shows the hypothetical function of the TebF protein, the action of maleylacetate reductase (MAR) and finally the steps to succinate and chloroacetate. Hypothetical steps are indicated by open or dotted arrows; characterized enzymatic catalyzations are indicated by closed arrows.

(ortho-) cleavage (e.g. catechol 1,2-dioxygenase), or extradiol (meta-) cleavage (e.g. catechol 2,3dioxygenase) (Harayama \& Rekik 1989). Chlorosubstituted catechols, which arise as intermediates in chlorobenzene degradation, are generally only successfully metabolized by the action of a series of enzymes, collectively referred to as the modified ortho cleavage pathway enzymes (Pieper et al.
1991; Reineke \& Knackmuss 1988; Schlömann et al. 1990; Schmidt \& Knackmuss 1980; Schmidt et al. 1980). This pathway leads probably to succinate and chloroacetate which are taken up in the central metabolic routes in aerobic microorganisms (Sander et al. 1991).

The metabolic details of the chlorobenzene pathway and that of other aromatic pathways suggested 

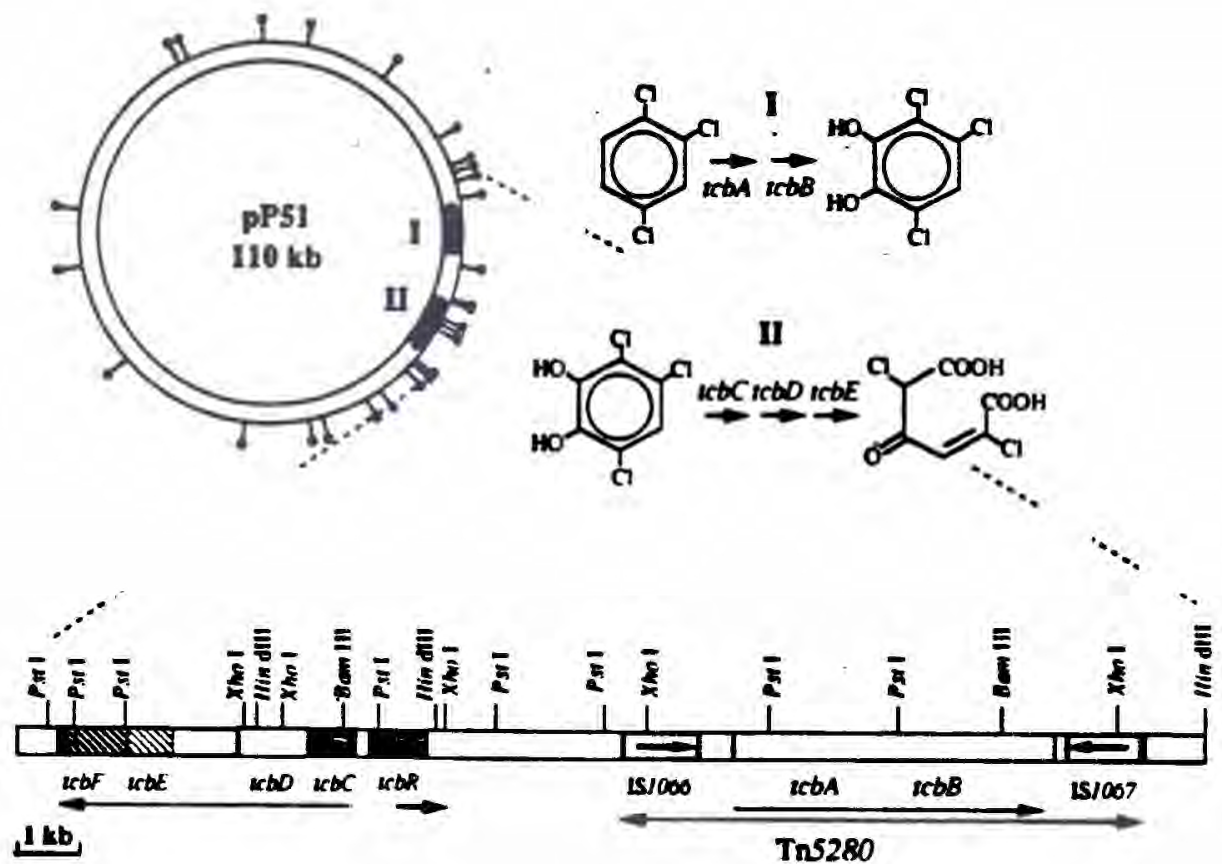

Fig. 8. Otganization of chlorobenzene genes on plasmid pP51 of Pseudomones sp. strain P51. The genes are located on the regions of the plasmid indicated by $I$ and II, encoding the respective conversions shown in the figure. The directions of transcription are indicated by the arrows below the physical map. For gene assignments, see main text (van der Meer et al. 1991a-d).

the steps which would be necessary for a microorganism to achieve full chlorobenzene metabolism. Firstly, microorganisms would need to express the enzymes of the modified ortho cleavage pathway. However, strains such as Pseudomonas sp. strain B13 which degrades 3-chlorobenzoate by modified ortho cleavage, lack an appropriate aromatic ring dioxygenase to oxygenate chlorinated benzenes effectively to chlorinated catechols (Oltmanns et al. 1988). Therefore, the desired strain needs an effective aromatic ring dioxygenase and a cis-benzeneglycol dehydrogenase. Microorganisms which grow on toluene, such as $P$. putida $F 1$, express a toluene dioxygenase which has a wide substrate range and is able to oxidize halogen-substituted benzenes (Gibson et al, 1990). However, in $P$. putida F1 catechol intermediates are cleaved by a catechol 2,3-dioxygenase and further degraded by the meta cleavage pathway enzymes. For most chlorosubstituted catechols this is an unproductive route and can lead to the formation of toxic intermediates (Bartels et al. 1984). Thus, a combination of a wide-substrate aromatic ring dioxygenase and benzeneglycol dehydrogenase in conjunction with a modified ortho cleavage pathway could be a successful way for microorganisms to metabolize chlorinated benzenes. Such a combination was achieved in the laboratory by mating two strains, one degrading toluene and the other degrading 3-chlorobenzoate (Kröckel \& Focht 1987; Oltmanns et al. 1988), and it was shown that in these cases the transfer of a plasmid containing the genetic information for one of the determinants (toluene degradation or 3-chlorobenzoate degradation) had occurred (Carney et al. 1989).

We decided that metabolism of chlorinated benzenes would be a good case to study genetic adaptation of microorganisms in the natural environment. In soil columns which were percolated with mixtures of DCBs and TCBs (see above) we found that adaptation to 1,2-DCB could occur, afier an initial period of up to 100 days without measurable degradation (van der Meer et al. 1987). From enrichments on 1,2-DCB, 1,4-DCB, and 1,2,4-TCB different microorganisms could be isolated which could use these compounds as the sole carbon and 
energy source (Schraa et al. 1986; van der Meer et al. 1991b). One of these strains, Pseudomonas sp. strain P51, was used for further characterization. We found that this strain induced modified ortho cleavage pathway enzymes when cultivated on 1,2,4-TCB or 1,2-DCB (van der Meer et al. 1991b). Bacteria which had been grown on chlorinated benzenes contained a large plasmid designated pP51, with a size of $110 \mathrm{~kb}$ (Fig. 8). This plasmid carried the genetic determinants for chlorobenzene degradation in strain P51. A genetic characterization of pP51 revealed two responsible regions: one for a modified orho cleavage pathway and the other containing the genes for a chlorobenzene dioxygenase and a cis-benzeneglycol dehydrogenase (van der Meer et al. 1991b). Subcloning experiments and expression studies in $E$. coli identified most of the genes for the modified ortho pathway enzymes. Further DNA sequence analysis revealed that this region contains five contiguous open reading frames of which three could be assigned to an enzymatic function: $t c b C$, encoding chlorocatechol 1,2-dioxygenase, $t c b D$, encoding chloromuconate cycloisomerase, and $t c b E$, encoding dienelactone hydrolase (van der Meer et al. 1991a). Another open reading frame ( $t c b F$ ) could be expressed in $E$. coli, but no enzymatic activity could be attributed to it. The primary sequence of the encoded TcbF polypeptide showed $30 \%$ identity with iron-containing alcohol dehydrogenases (van der Meer, unpublished), which suggests a possible function for TcbF (Fig. 7). A fifth open reading frame was found between the $t c b D$ and $t c b E$ gene, but this was not transcribed in $E$. coli. The DNA sequences of the $t c b C D E F$ genes were between $50 \%$ and $75 \%$ identical 10 gene clusters for other modified ortho pathways (van der Meer et al. 1991a), such as clcABD of $P$. putida (pAC27) (Frantz \&Chakrabany 1987) and ifdCDEF of $A$. eutrophus JMP134 (pJP4) (Perkins et al. 1990). Furthermore, the genes of the modified ortho cleavage pathway were distantly related to those of the normal ortho cleavage pathway, which is found in many organisms growing on benzoate or hydroxybenzoate, suggesting an evolutionary relation and divergence of the two gene clusters from a common ancestor (van der Meer et al. 1991a). The enzymes of the modified ortho cleavage pathway catalyze conversion reactions that are analogous to those of the normal ortha cleavage pathway (Ornston et al. 1990; Reineke \& Knackmuss 1988). However, in the modified ortho cleavage route enzymes occur which are not found in the normal ortho cleavage route and vice versa, such as dienelactone hydrolase (Fig. 7), whereas others, such as chlorocatechol 1,2-dioxygenase and chloromuconate cycloisomerase have relatives in the normal ortho cleavage pathway. The enzymes of the modified ortho cleavage pathway were in all cases described so far, less substrate-specific than their counterparts in the normal ortho cleavage pathway and could accomodate the chlorinated intermediates better than the non-chlorinated ones (Broderick \& O'Halloran 1991; Kuhm et al. 1990; Ngai \&Ornston 1988; Pieper et al. 1991). Analysis of catalytic activities of chlorocatechol 1,2-djoxygenases and of chloromuconate cycloisomerase activities indicated that there was a further subtle specialization of these enzymes to specific substrates (Kuhm et al. 1990; van der Meer et al. 1991a). For instance, chlorocatechol 1,2-dioxygenase of Pseudomonas sp. strain P51 showed a higher relative activity towards the substrate 3,4-dichlorocatechol than to the other dichlorinated catechols, whereas the chlorocatechol 1,2-dioxygenase of $A$. europhus JMP134 exhibited a higher relative activity to 3,5-dichlorocatechol. These datal suggest that the chlorocatechol 1,2-dioxygenases of the different strains became evolutionary optimized for specific substrates, e.g. the intermediate 3,4-dichlorocatechol in 1,2-DCB degradation, and 3,5-dichlorocatechol in the degradation of 2,4-dichlorophenoxyacetic acid. Analysis of DNA sequence information suggests that the intradiol dioxygenases may have diverged via a mechanism of slippage-repair rather than via additive single-site mutations (Harnett et al. 1990; Neidle et al. 1988; Ornston et al. 1990).

Genetic analysis of the genes encoding the chlorobenzene dioxygenase and the chlorobenzenegly$c o l$ dehydrogenase (tentatively named $t c b A$ and tcbB) of Pseudomonas sp. strain P51 revealed another interesting aspect (van der Meer et al. 1991c). Southern hybridizations and subsequent DNA sequence information showed that a duplicated and 


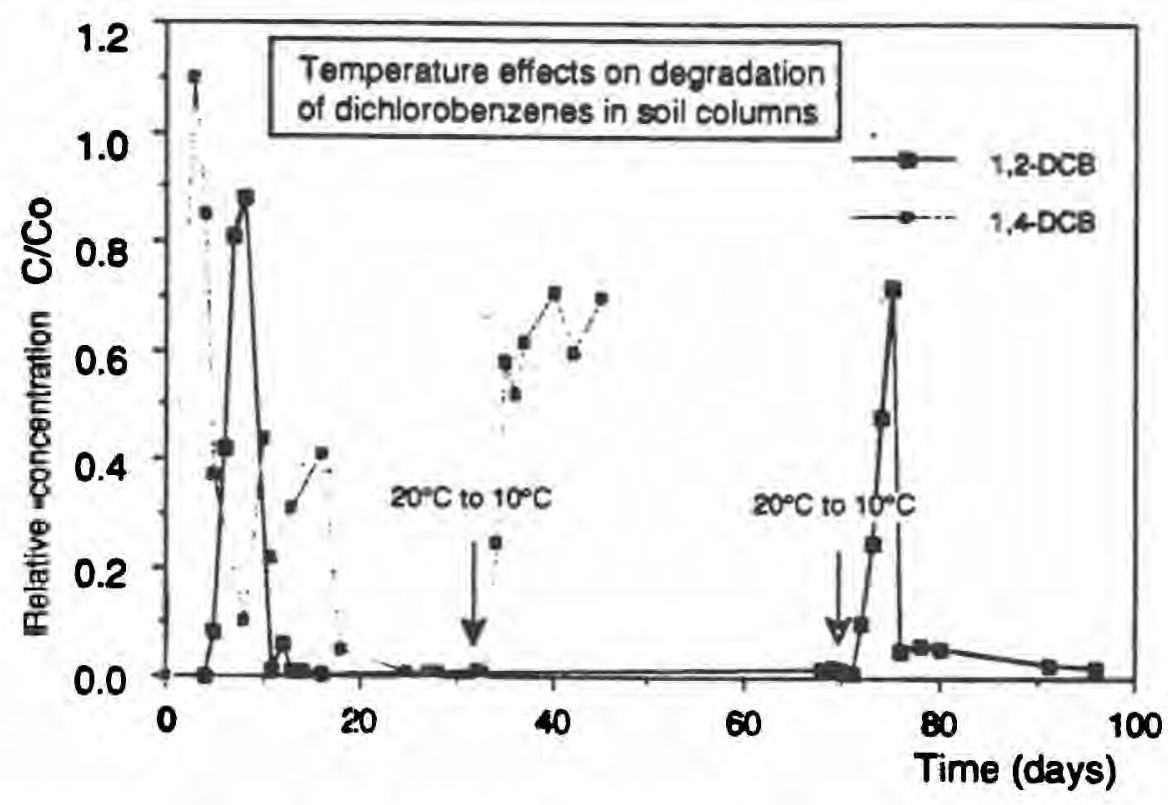

Fig. 9. Temperature effects on biodegradation of 1,2-DCB and 1,4-DCB in a naturally adapted column and an inoculated column, respectively. The experiment shown here started after the naturally adapted column to 1,2-DCB had been operated for 200 days continuously, and then for a period of 28 days had received no 1,2-DCB. After the addition of 1,2-DCB at a concentration of $25 \mathrm{\mu g} / \mathrm{lo}$ the column, the biological activity was restored within ten days operation. The column receiving 1,4-DCB (at a concentration of $25 \mu \mathrm{g} /$ ) was inoculated with Alcaligenes sp. strain A175 (Schraa et al. 1986). At the time points indicated, the columns wete changed from an operating temperature of $20^{\circ} \mathrm{C}$ to $10^{\circ} \mathrm{C}$. Concentration measurements of dichlorobenzenes were done in the effluent of the columns, and are represented in the figure as the relative concentration measured in the effluent compared to the influent concentrations $\left(C / C_{0}\right)$. Redrawn after (Bosma et al., in preparation).

inverted discrete DNA fragment was flanking the $t c b A B$ gene loci. This fragment had a size of $1.1-\mathrm{kb}$ and both copies were identical except for one basepair. The sequence showed one open reading frame encoding a putative polypeptide with homology to polypeptides encoded by insertion elements (van der Meer et al. 1991c). Therefore, we designated these elements 13.1066 and IS1067. This suggested that the DNA fraginent containing $t c b A B$ plus the putative IS elements were a composite bacterial transposon. We were able to demonstrate that this transposable element, $\operatorname{Tn} 5280$, was functional and transposed at random and in single copy to the genome of $P$. putida (van der Meer et al. 1991c). These results suggested that perhaps the genes encoding the chlorobenzene-dioxygenase and chlorobenzeneglycol dehydrogenase were recruited through the mediation of IS-elements by an ancestor plasmid of pP51, which already contained the genes encoding a modified ortho pathway. At present, we have not analyzed the origin of the IS elements IS1066 and IS1067 or the dioxygenase gene fragment in other bacterial species. However, preliminary studies which applied the technique of DNA-DNA colony hybridization (Sayler et al. 1985) with genetic markers from chlorobenzene degradation genes indicated the presence of other microorganisms in the original soils used for the column experiments, which carried genetic material homologous to the $t c b$ genes.

The use of pure cultures or enrichment cultures to enhance biodegradation

Many attempts are made to evaluate the possibilities of applying pure cultures or enriched bacterial strains to enhance biodegradation of recalcitrant compounds in the environment. On the level of the bacterial strains, such efforts are directed to either isolate by enrichment techniques specific strains that will perform the desired metabolic conver- 
sions, or to construct strains by genetic means that will allow degradation of a previously considered unmetabolizable substrate (Latorre et al. 1984; Lehrbach et al. 1984; Rojo et al. 1987). However, as we have seen above, the success (or failure) to enhance biodegradation of specific compounds in the environment, does not depend solely on the catabolic potential of the microorganisms used. This section will deal with the effects of temperature-related activity and adhesion properties of microorganisms on the use and application of pure cultures in biodegradation.

We evaluated the use of two different pure cultures capable of metabolizing chlorinated benzenes, Pseudomonas sp. strain P51 and Alcaligenes sp. strain A175, to decontaminate low concentrations of DCBs and TCBs from percolated water in a soil column. Strain Pseudomonas sp. P51 was pregrown on 1,2,4-TCB and introduced into the soil column and was able to degrade different concentrations of DCBs and 1,2,4-TCB to a low, albeit detectable, level (see above). This microorganism remained active in degrading chlorinated benzenes as long as these compounds were present. How. ever, a 28-day period without addition of fresh substrates resulted in a loss of the degradative ca. pacity of the strain in the column. The activity of strain P51 in the column gave further evidence for chemotactic migration of the strain towards the substrates added in the influent (Bosma et al. 1988b). A soil column in which degradation of 1,2-DCB occurred after adaptation of the natural population, was able to restore the 1,2-DCB degradation activity after a period without substrate added (Fig. 9). In a new soil column which was inoculated with another chlorobenzene degrading strain, Alcaligenes sp. strain A175, we also found that the cells were able to retain their activity in the soil column and could degrade 1,4-DCB almost completely (Fig. 9). The effect of temperature on the biodegradation of 1,2-DCB and 1,4-DCB in the naturally adapted and this inoculated column was then examined by changing the operating temperature of the columns from $20^{\circ} \mathrm{C}$ to $10^{\circ} \mathrm{C}$ (Bosma et al., in preparation). The column which was in-oculated with Alcaligenes sp. strain A175 was immediately disturbed in the degradation of $1,4-$
DCB, and after a 10-day period a new equilibrium was reached (Fig. 9). However, the total removal of 1,4-DCB after this change was only about $40 \%$ of the influent concentration applied to the column. The response of the naturally adapted $c o$ lumn was initially similar to the inoculated column. A rapid decrease in 1,2-DCB removal was observ$e d$, and after a 10-day period the previous steady state concentration of 1,2-DCB was restored in the effluent of the column (Fig. 9). This demonstrated that the bacteria in this column were better suited to be active at lower temperatures. Changing the temperature of this column to an even lower value of $4^{\circ} \mathrm{C}$ did not alter the steady state concentrations measured for 1,2-DCB (not shown).

A similar temperature response was found for soil columns which were inoculated with Rhodococcus sp. strain $\mathrm{C} 125$, a strain which can use toluene and 1,3-dimethylbenzene as the sole carbon and energy substrates (Schraa et al. 1987). Changing the operating temperature from $20^{\circ} \mathrm{C}$ to $10^{\circ} \mathrm{C}$ again resulted in disturbance of the degradation of toluene and 1,3-dimethylbenzene in the column. Whereas at $20^{\circ} \mathrm{C}$ more than $90 \%$ of the influent concentrations of these compounds could be degraded (around $500 \mu \mathrm{g} /$ ), only 20 to $30 \%$ removal was observed at $10^{\circ} \mathrm{C}$ (Fig. 10). Enrichment cultures were started at a temperature of $10^{\circ} \mathrm{C}$, using contaminated soil from a petrol station as source for microorganisms (de Bruin, unpublished). Within three weeks, growth of the enrichments on toluene, 1,3- and 1,2-dimethylbenzene was observed, and the mixed cultures were added to the soil columns. Toluene and 1,3-dimethylbenzene were then easily degraded in these columns at a temperature of $10^{\circ} \mathrm{C}$ to levels as low as those at $20{ }^{\circ} \mathrm{C}$ (Fig. 10). Temperatures of $10^{\circ} \mathrm{C}$ are more often encountered in ground water than temperatures of $20^{\circ} \mathrm{C}$, and our results demonstrate that use of pure cultures which have been isolated on the basis of their faster growth rate at higher temperatures, can thus be limited in on-site applications.

Application of microorganisms in bioreactors or in groundwater systems will also require information about the adhesion of bacteria to solid particles and deposition in porous media. If, for instance, the introduced microorganisms do not ad. 


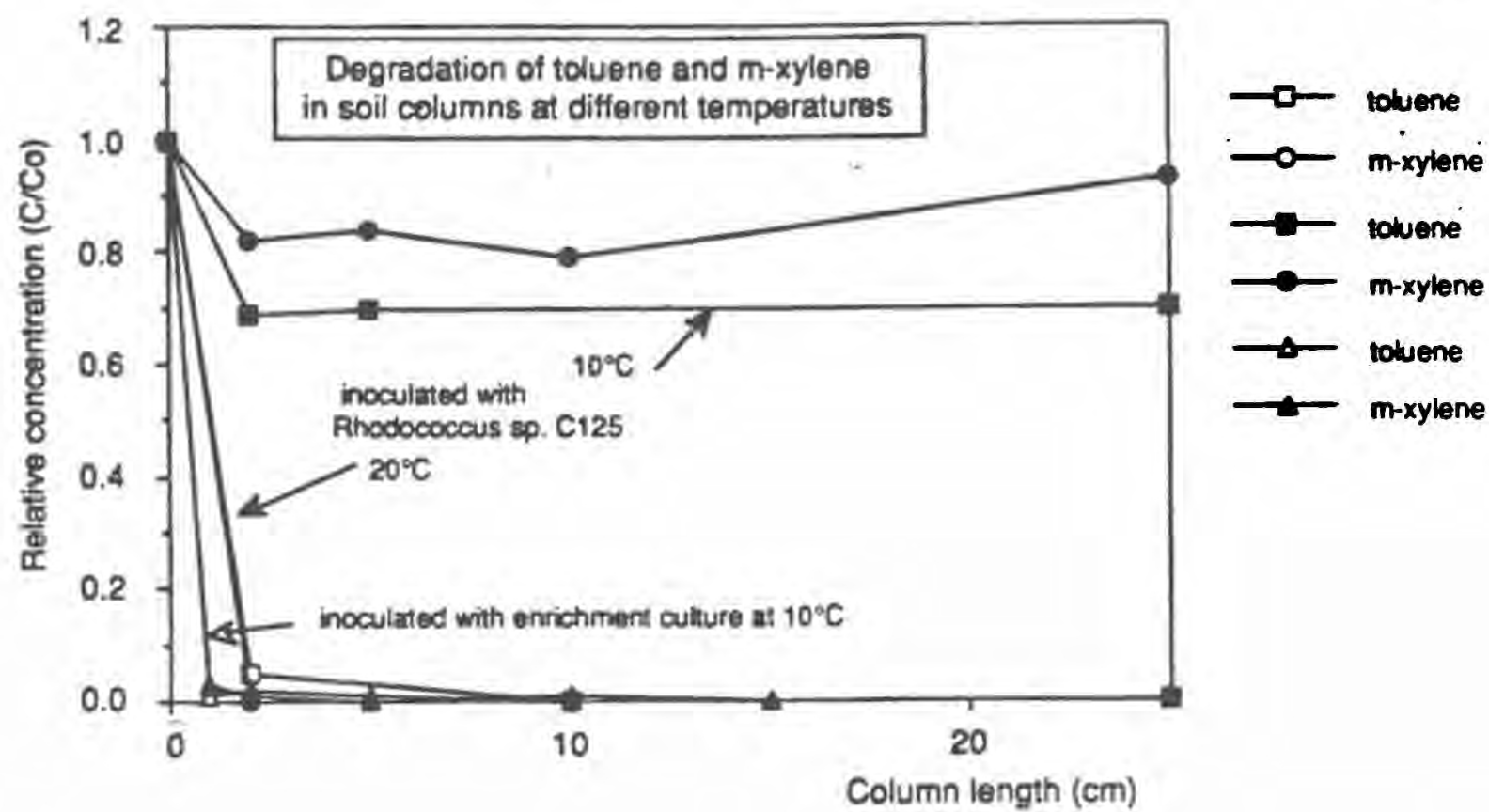

Fig. 10. Temperature effects on toluene and 1,3-dimethylbenzene degradation in soil-slurry columns, either inoculated with Rhodococcus sp. strain C125 (Schraa et al., 1987), or inoculated with a low remperature adapted enrichment. Influent concentrations of toluene and xylene measured approximately $500 \mathrm{\mu g} /$.

here to the solid phase, they are not retained in a reactor or are transported in the soil with the water flow, and this may diminish the necessary desired biodegradation. Fundamental information about adhesion of microorganisms, which are regarded in this respect as colloidal particles, can be derived from batch and column experiments. The adhesion properties of microorganisms to well-defined surfaces such as glass, polystyrene, or teflon in batch systems was studied previously and shown to be controlled by repulsive electrostatic and attractive van der Waals forces, as described by the DLVO theory for colloidal particles (van Loosdrecht et al. 1989). The physico-chemical properties of the microorganisms can be experimentally studied by measuring their electrophoretic mobility (which characterizes the surface charge of the microorganism, van Loosdrecht et al. 1987a), and the contact angle of a drop of water on dried bacterial lawns (which provides information on the hydrophobicity of the organism, van Loosdrecht et al. 1987b). In dynamic systems, such as columns, adhesion of microorganisms is not only affected by surface characteristics but also by the hydrodynamic factors controlling transport of the particle from the bulk liquid phase to the solid surface (Rijnaarts et al., in preparation).

The adhesion of a number of bacterial strains was studied in mare detail in column experiments, which contained the surface materials glass (a hy. drophilic material), and teflon (PFA-teflon, an extremely hydrophobic material). Both surfaces are negatively charged and possess an electrokinetic potential of $-42 \pm 2 \mathrm{mV}$ at an ionic strength of $0.01 \mathrm{M}$ (Rijnaarts, unpublished). Thi se bacterial strains were tested, Pseudomonas sp. strain B13, $\boldsymbol{P}$. putida $\mathrm{mt}-2$ and Sphingomonas sp. strain HH19K (which degrades dibenzofuran) (Fortnagel et al. 1990), each having different cell surface characteristics. The contact angles of water observed for the three species varied from $32^{\circ}$ for strain B13, $40^{\circ}$ for strain mt-2, to $60^{\circ}$ for Sphingomonas, indicating that this last strain was the most hydrophobic of the three. The electrophoretic mobilities at an ionic strength of $0.01 \mathrm{M}$ measured $-2.1 \cdot 10^{-8}$, $-1.1 \cdot 10^{-8}$, and $-1.6 \cdot 10^{-8} \mathrm{~m}^{2} \cdot \mathrm{V}^{-1} \cdot \mathrm{s}^{-1}$, respectively. 


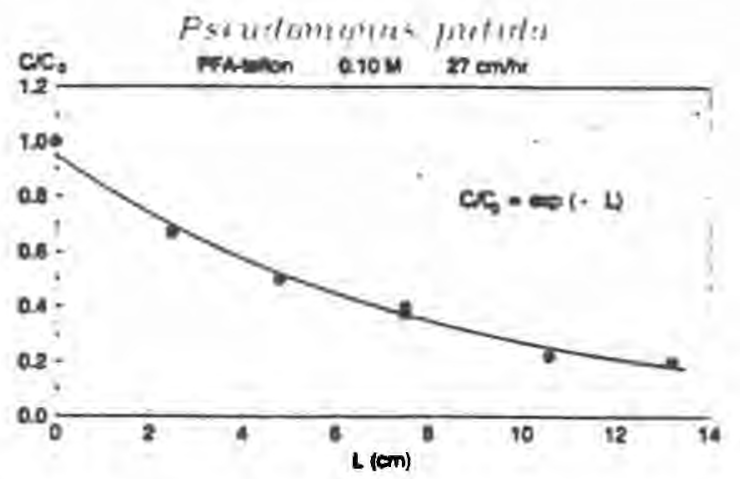

Fig. 11. Determination of the retention of $P$. purida in a PFAteflon bead column. The decrease of cell numbers present in the liquid phase is indicated as a decrease in cell numbers per mi at a certain point in the column (C) compared to the numbers per ml in the influent $\left(C_{0}\right)$. This decrease can be described using the exponential decay equation indicated, whereby $L$ is the length of the column, and $\lambda$ the filtration coefficient. Ionic strength of the liquid phase was $0.1 \mathrm{M}$, and flow rate imposed on the face of the column $27 \mathrm{~cm} / \mathrm{h}$.

This indicated that strain B13 beared the highest surface charge. The columns were packed with spherical collectors of teflon and glass with an average radius of $0.2 \mathrm{~mm}$. Bacterial suspensions of $10^{8}$ cells per $\mathrm{ml}$ were fed to these columns and the cell numbers in the influent and the effluent of the columns were measured. After a number of pore volumes a steady state was reached resulting in a constant aqueous cell concentration at a specific location in the column. This normalized concentration' of cells (which is the ratio of the effluent concentration over the influent concentration, $\mathrm{C} / \mathrm{C}_{0}$ ) decreases exponentially with the length of the column (Fig. 11), with a decay constant termed the filtration coefficient $\lambda\left(\mathrm{m}^{-1}\right)$. The obtained filtration coefficients for the three strains at different ionic strengths and with two different surfaces, glass and teflon, showed interesting differences and have important implications for the behaviour of these strains (Fig. 12). Pseudomonas sp. strain B13 appeared to be a very poor adhering microorganism. Due to its hydrophilic nature and higher surface charge, the organism adheres better on hydrophilic surfaces (such as glass) than on hydrophobic ones (such as PFA-teflon). Changing the ionic strength of the liquid phase does not dramatically alter this adherence (Fig. 12). The organism

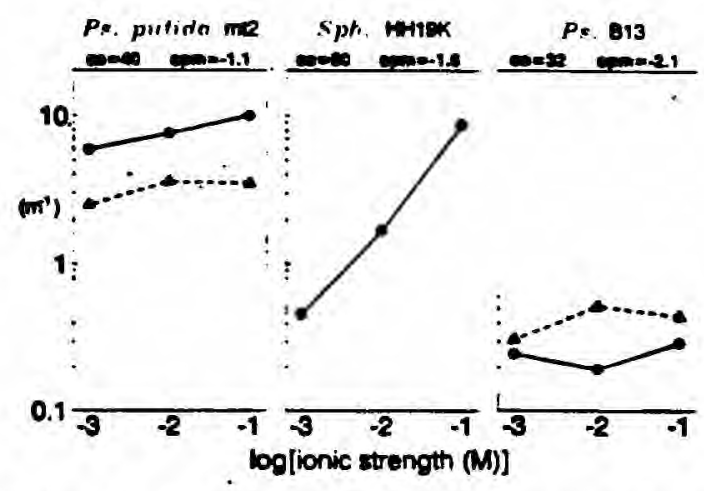

Fig. 12. Fitration coefficients determined from column adbesion experiments for three difierent microotganisms, $P$. putida mt-2, Sphingomones sp. strain HH19K, and Pseudomonas \$p. strain B13 under different ionic strengths and on two different surfaces, PFA-tetion (circles) and glass (triangles). The Ggure shows further cell surface characteristics of the microorganisms: the contact angle (ca, expressed in degrees), and the

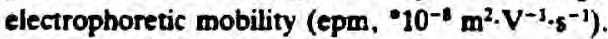

can hardly be retained in columns such as described in these adhesion experiments. Similar observations were made when this strain was applied in soil columns. Wash-out of the strain from the column resulted in a very poor degradation of $3 \mathrm{CB}$. In contrast, $\boldsymbol{P}$. putida $\mathrm{mt}-2$ which is a moderately hydrophilic, low-charged bacterium. behaved as a very good adhering organism both to hydrophilic and hydrophobic column material (Fig. 12). Results with Sphingomonas sp. strain HH19K demonstrated that ionic strength can determine the adherence of a strain to the solid matrix. This organism adhered poorly at low ionic strengths, but retained better at higher ionic strength $(0.1 \mathrm{M})$.

\section{Concludi.g remarks}

Our studies have demonstrated the usefulness of soil column experiments to evaluate various aspects of biodegradation of halogenated compounds in an infiltration site. The system can be operated easily under variable conditions found in the environment (temperature, redox state, concentration of the compounds, etc.), and once biodegradation is initiated, the column can be used to enrich for microorganisms with the desired characteristics. Many interesting aspects were discovered and in- 
vestigated further, such as (i) the isolation of anaerobic microorganisms which derive energy from reductive dechlorination of tetrachloroethylene or 1,2,3-rrichlorobenzene, (ii) the occurrence and nature of residual concentrations and their effect on biodegradability, (iii) genetic adaptation to chlorinated benzenes, and (iv) the strong temperature effects on biodegradability of inoculated strains, and the effects of adherence properties of bacterial strains on their retainment.

Considering the possibilities to use naturally adapted or genetically engineered strains to combat pollution, we have shown that the success (or failure) to enhance biodegradation of specific compounds depends on various biological and physicochemical factors. In natural systems the environmental conditions will determine to a large extent the activities that microorganisms can display. Suitable microorganisms must be present to carry out the complete degradation, but different redox conditions (anaerobic, aerobic) will influence what type of biodegradation prevails, and this may favour particular transformation reactions (e.g. reductive dechlorination of polychlorinated benzenes and biphenyls in sediments), whereas others are repressed (e.g. aerobic conversion of lower chlorinated benzenes or biphenyls). We have shown that microorganisms in the natural environment can adapt to novel substrates, such as chlorinated benzenes. Therefore, to stimulate biodegradation in the natural environment it may be a good strategy to create optimal conditions for the activity of indigenous microorganisms. This may also enhance adaptation of suitable microorganisms, however, it is not thoroughly investigated what the full catabolic potential of microorganisms in the environment is (van der Meer 1992).

Under specific circumstances, such as in treatment systems, it may be more effective to apply specifically engineered or enriched strains. However, several aspects must be evaluated to obtain successful biodegradation. In on-site applications the desorption rates of the pollutants from the solid matrix may be rate-determining for biodegradation. Furthermore, biodegradation may be hampered in specific treatment systems due to growth kinetic parameters of the bacterial strains used.
When the available concentration of the substrates becomes too low to sustain growth, a residual concentration of the pollutant may remain. The best strains to use in treatment systems are not necessarily those that have been isolated for their fastest growth rate at higher temperatures $\left(20^{\circ} \mathrm{C}\right.$ to $30^{\circ} \mathrm{C}$ ). Depending on the temperature that is needed for the application, it is often better to enrich for low-temperaturt adapted strains or populations from the envircnment. Finally, the adhesion properties of the isolated microorganisms should be investigated to allow optimal retention of the $\mathrm{mi}$ crobial strains in the system.

\section{Acknowledgements}

This work was financed by grants from The Netherlands Integrated Soil Research Programme and the Innovative Research Program on Environmental Biotechnology.

\section{References}

Aelion CM, Swindoll CM \& Pfaender FK (1987) Adaptation 10 and biodegradation of xenobiotic compounds by microbial communities from a pristine squifer. Appl. Environ. Microbiol. 53: 2212-2217

Alexander M (1985) Biodegradation of organic chemicals. Environ. Sci. Technol. 18: 106-111

Bachmann A, de Bruin WP. Jumelet JC, Rijnars HHM \& Zehnder AJB (1988) Aerobic mineralization of alpha-hexachlorocyclohexane in contaminated soil. Appl. Environ. Microbiol. S4: S48-554

Burkay T \& Pritchard H (1988) Adaptation of aquatic microbial communities to pollutant stress. Microbiol. Sci. 5: 165-169

Bartels I, Knackmuss H-J \& Reineke W (1984) Suicide inactivation of catechol 2,3-dioxygenuse trom Pseudomonas pufidemi-2 by 3-halocatechols. Appl. Environ. Microbiol. 47: soO-sOS

Bosma TNP, Holliger C, van Neerven ARW, Schraa G \& Zehnder AJB (1988a) Reductive dechlorination of chlorinated bydrocartons in anaerobic sediment columns. In: Wolf $K$, van den Brink WJ Colon FJ (Eds) Cootaminated Soil '88 (pp 731-732). Kuwer Academic Publisherr, Dordrecht

Bosma TNP, Schnoor JL, Schraa G \& Zehnder AJB (1988b) Simulation model for biotransformation of xenobiotics and chemotaxis in soil columns. J. Contam. Hydrol. 2: 225-236

Bosma TNP. van der Meer JR, Schraa G. Tros ME \& Zehnder 
AB (1988) Rechuctive dechlorinntion of all trichloro- and dichlorobenzene isomers. FEMS Microbiol. Ecol. 53: 223-229

Bosma INP, te Welscher RAG, Schraa G, Smeenk JGMM \& Zehnder AJB (1991) Microbial upects of the behaviour of chlorinated compounds during soil pascage. In: Angeletti $G$ and Bjorseth A (Eds) Organic Micropollutants in the Aquatic Environment (pp 184192). Kluwer Academic Publishers, Dordrecht

Bosma INP, te Welscher RAG, Smeenk JGMM, Ballemans EMW, Hoekstra NK, Schras G Zehnder AJB (in preparation) Biotransformation of organic contaminants in a dune infiltration area and in sediment columns.

Broderick JB \& O'Halloran TV (1991) Overproduction, purification, and characterization of chlorocatechol dioxygenase, a non-heme iron dioxygenase with broad substrate tolerance. Biochemistry 30: 734-7358

Carney BF, Krókel L, Leary JV \& Focht DD (1989) Identification of Pseudomonas alcaligenes chromosomal DNA in the plasmid DNA of the chlorobenzene-degrading recombinant Pseudomonas putida strain CB1-9. Appl. Environ. Microbiol. 55: 1037-1039

Chaudry GR \& Chapalamadugu S (1991) Biodegradation of halogenated organic compounds. Microbiol. Rev. 55: 59-79

Chesbro W, Evans T \& Eifer R (1979) Very slow growth of Escherichia coli. J. Bacteriol. 139: 625-638

Commandeur LCM \& Parsons JR (1990) Degradation of halogenated aromatic compounds. Biodegradation 1: 207-220

de Bruin WP, Kottermann MJJ, Posthumus MA, Schraa G \& Zehnder AJB (1992) Complete biological reductive transformation of tetrachloroethene to ethane. Appl. Environ. Microbiol. 58: 1996-2000

Don RH \& Pemberion JM (1981) Properties of six pesticide degradation plasmids isolated from Alcaligenes paradoxus and Alcaligenes eutrophus. J. Bacteriol. 145: 681-686

Faulkner DJ (1980) Natural organohalogen compounds. In: Hutzinger $O$ (Ed) The Handbool of Environmental Chem. istry, 1A. The Natural Environment and the Biogeochemical Cycles. Springer Verlag. New York

Fortnagel P, Harms H, Wittich R-M. Krohn S, Meyer H, Sinnwell V, Wilkes H \& Francke W (1990) Metabolism of dibenzofuran by Pseudomonas sp. strin HH69 and the mized culture HH27. Appl. Environ. Mictobiol. S6: 1148-1156

Frantz B \& Chakrabarty AM (1987) Organization and nucleotide sequence determination of a gene cluster involved in 3-chiorocatechol degradation. Proc. Natl. Acad. Sci. USA. 84: $4460-4464$

Furukawa K, Matsumura F \& Tonomura K (1978) Alcaligenes and Acinetobacter strains capable of degrading polychlorinated biphenyls. Agric. Biol. Chem. 42: 543-548

Gibson DT, Zylstra GJ \& Chauhan SS (1990) Biotransformations catalyzed by toluene dioxygenase from Pseudomonas purida F1. In: Silver S, Chakrabanty AM, Iglewski B \& Kaplan S (Eds) Pseudomonas: Biotransformations, Pathogenesis and Evolving Biotechnology (pp 121-133). American Society for Mictobiology. Washington. DC

Goldstein RM, Mallory LM \& Alexander M (1985) Reasons for possible filure of inoculation to enhance biodegradation. Appl. Environ. Microbiol. 50: $977-983$

Haggblom M (1990) Mechanisms of becterial degradation and transformation of chlorinated monoaromatic compounds. J. Basic. Microbiol. 30: 115-141

Harayama S \& Rekik M (1989) Bacterial aromatic ring-cieavage enzymes are classified into two different gene families. J. Biol. Chem. 264: 15328-15333

Hartnett C, Neidle EL, Ngaj K-L \& Ornston LN (1990) DNA sequences of genes encoding Acinetobacter calcosceticus protocatechunte 3,4-dioxygenase: evidence indicating shuffling of genes and of DNA sequences within genes during their evolutionary divergence. J. Bacteriol. 172: 95-966

Holliger C (1992) Reductive dehalogenation by anaerobic bacteria. Ph.D. Thesis, Wageningen Agricultural University. Wageningen, The Netherlands

Holliger C, Schran G, Stams AJM \&Zehnder AJB (1992) Enrichment and properties of an anaerobic mixed culture reductively dechlorinating 1,2,3-trichlorobenzene to 1,3-dichlorobenzene. Appl. Environ. Microbiol. 58: 1636-1644

Huntjens JM, Brouwer W, Grobben K, Jansma O, Scheffer F \& Zehnder AJB (1988) Biodegradation of a-hexachlorocyclobexane by a bacterium isolated from polluted soil. In: Wolf $K$. van den Brink W J \& Colon FJ (Eds) Contaminated Soil '88. Kuwer Academic Publishers, Dordrecht

Karns JS, Kilbane JJ, Duttagupta S \& Chakrabarty AM (1983). Metabolism of balophenols by 2,4,5-trichlorophenoxyacetic acid-degrading Pseudomonas cepacia. Appl. Environ. Microbiol. 46: 1176-1181

KJein TM \& Alexander M (1986) Bacterial inhibitors in lake water. Appl. Environ. Mictobiol. 52: 114-118

Kröckel L \& Focht DD (1987) Construction of chlorobenzeneutilizing recombinants by progenitive manifestation of a rare event. Appl. Environ. Microbiol. 53: 2470-2475

Kuhm AE, Schö́mann M, Knackmuss H.J \& Pieper DH (1990) Purification and characterization of dichloromuconate cycloisomerase from Alcaligenes eutrophus JMP134. Biochem. J. 266: $877-883$

Latorre J, Reineke W \& Knackmuss H-J (1984) Mictobial metabolism of chloroanilines: enhanced evolution by naturally' genetic exchange. Arch. Mictobiol. 140: 159-j65

Lehrbach PR. Zeyer J, Reineke W, Knackmuss H.J \& Timmis KN (1984) Enzyme recruitment in vitro: use of cloned genes to extend the range of haloaromaies degraded by Pseudomonas sp. strain B13. J. Bacteriol. 158: 1025-1032

Mondello FJ (1989) Cloning and expression in Escherichia coli of Pseudomonas strain LB400 genes encoding polychlorinated biphenyl degradation. J. Bacteriol. 171: 1725-1732

Neidle EL; Hantuet C, Bonitz S \& Ornston LN (1988) DNA sequence of the Acinerobacier calcoacericus catechol 1.2-dioxygenase I structural gene catA: evidence for evolutionary divergence of intradiol dioxygenases by acquisition of DNA sequence repetitions. J. Bacteriol. 170: $4874-4880$

Neilson AH (1990) The biodegradation of halogenated organic compounds - a review. J. Appl. Bacteriol. 69: 445-470

Ngaj K-L 2 Ornston LN (1988) Abundant expression of Pseu- 
domonas genes for chlorocatechol metabolism. J. Bacteriol 170: 2412-2413

Olumanns RH, Rast HG \& Reineke W (1988) Degradation of 1,4 -dichlorobenzene by constructed and enriched strains Appl. Microbiol. Biotechnol. 28: 609-616

Ornston LN. Houghton J, Neidle EL \& Gregg LA (1990) Subtle selection and novel mutation during evolutionary divergence of the B-ketoadipate pathway. In: Silver S, Chakrabarty AM, Iglewski B \& Kaplan S (Eds) Pseudomonas: Biotransformations, Pathogenesis and Evolving Bjotechnology (pp 207225). American Society for Mictobiology, Washington. DC

Pearson CR (1982) $\mathrm{Cl}$ and $\mathrm{C}$ halocarbons. In: Hutzinger $O$ (Ed) The Handbook of Environmental Chemistry, 3B (pp 69-88). Springer Verlag. New York

Perkins EJ, Gordon MP. Caceres O \& Lurquin PF (1990) Organization and sequence analysis of the 2,4-dichlorophenol hydroxylase and dichlorocatechol oxidative operons of plasmid pJP4. J. Bacteriol. 172: 2351-2359

Pieper DH, Kuhm AE, Stadlet-Fritache K. Fischer P \& Kackmuss H-J (1991) Metabolization of 3,5-dictlorocatechol by A/caligenes eurrophus JMP 134. Arch. Microbiol. 156: 218-222

Pirt SJ (1975) Principles of Microbe and Cell Cultivation. Blackwell Scientife Publications. Oxford

Reineke W \& Knackmuss H-J (1984) Microbial metabolism of haloaromatics: isolation and properties of a chlorobenzenedegrading bacterium. Appl. Environ. Microbiol. 47: 395-402

Reineke W \& Knackmuss H-J (1988) Microbial degradation of haloaromatics. Annu. Rev. Microbiol. 42: 263-287

Rijnaarts H. Norde W, Bouwer E. Lyklema J \& Zehnder AJB (in preparation) Reversibility of bacterial adhesion: studies with various strains of Pseudomones and coryneform bacteria

Rijnaarts HHM. Bachmann A. Jumelet JC \& Zehnder AJB (1990) Effect of the desorption and intraparticle mass transfer on the aerobic biomineralization of $a$-hexachlorocyclohexane in a contaminated calcareous soil. Environ. Sci. Technol. 24: $1349-1354$

Rojo F. Pieper DH. Engesser K-H, Knackmuss H-J \& Timmis KN (1987) Assemblage of ortho cleavage route for simultaneous degradation of chloro- and methylaromatics. Science 238 : 1395-1398

Sander P. Wittich R-M. Fornagel P. Wilkes H \& Francke $\mathbf{W}$ (1991) Degradation of 1.2.4-trichloro- and 1.2.4.5-tetrachloobenzene by Pseudomonas strains. Appl. Enviton. Microbiol. 57: 1430-1440

Sayler GS. Shields MS. Tedford ET. Breen A. Hooper SW. Sirotkin KM \& Davis JW (1985) Application of DNA-DNA colony hybridization to the detection of catabolic genotypes in environmental samples. Appl. Enviton. Microbiol. 49: 1295-1303

Schlömann M. Pieper DH \& Knackmuss H-J (1990) Enzymes of haloaromatics degradation: variations of Alcaligenes on a theme by Pseudomonas. In: Silver S. Chakrabarty AM. Iglewski B \& Kaplan S (Eds) Pseudomonas: Biotransformations. Pathogenesis. and Evolving Biotechnology (pp 185197). American Society for Microbiology. Washington. DC

Schmidt E \& Knackmuss H.J (1980) Chemical structure and biodegradability of halogenated aromatic compounds. Conversion of chlorinated muconic scids into maleoylacetic acid. Biochem. J. 192: 339-347

Schmidt E, Remberg G \& Kackmuss H-J (1980) Chemical structure and biodegradability of halogenated aromatic compounds. Halogenated muconic acids as intermediates. Biochem. J. 192: 331-337

Schran G, Bethe B, van Neerven ARW, van den Tweel WJJ, van der Wende $E$ \& Zehnder AJB (1987) Degradation of 1.2-dimethylbenzene by Corynebacterium strain C125. Anthonie van Leeuwenhoek 53: 159-170

Schran G, Boone ML, Jetten MSM, van Neetven ARW, Colberg PJ \& Zehnder AJB (1986) Degradation of 1,4-dichiorobenzene by Alcaligenes sp. strain A175. Appl. Environ. Microbiol. 52: 1374-1381

Schwarzenbach RP \& Westall J (1981) Tranpont of non-polar organic compounds from surface water to groundwater: laboratory sorption studies. Environ. Sci. Technol. 15: 1360-1367

Spain JC \& Nishino SF (1987) Degradation of 1,4-dichlorobenzene by a Pseudomonas sp. Appl. Environ. Microbiol. 53: 1010-1019

Sullita JM. Horowitz A. Shelton DR \& Tiedje JM (1982) Dehalogenation: a novel pathway for the anaerobic biodegradation of haloaromatic compounds. Science 218: 1115-1117

Swindoll CM. Aelion CM \& Pfaender FK (1988) Influence of inorganic and organic nutrients on aerobic biodegradation and on the adaptation response of subsurface microbial communities. Appl. Environ. Microbiol. S4: 212-217

van der Meer JR (1992) Molecular mechanisms of adaptation of soil bacteria to chlorinated benzenes. Ph.D. Thesis. Wageningen Agricultural University, Wageningen. The Netherlands van der Meer JR. Roelofsen W, Schraa G Zehnder AJB (1987) Degradation of low concentrations of dichlorobenzenes and 1.2.4-trichlorobenzene by Pseudomonas sp. strain P51 in nonsterile soil columns. FEMS Microbiol. Ecol. 45: 333-341

van der Meer JR. Eggen RIL, Zehnder AJB \& de Vos WM (19918) Sequence analysis of the Pseudomonas sp. strain PS1 Icb gene cluster. which encodes metabolism of chlorinated catechols: evidence for specialization of catechol 1.2-dioxygenases for chlorinated substrates. J. Bacteriol. 173: 2425-2434

van der Meer JR, van Neerven ARW, de Vries EJ, de Vos WM \& Zehnder AJB (1991b) Cloning and characterization of plasmid-encoded genes for the degradation of 1,2-dichloro-, 1.4-dichloro- and 1.2,4-trichlorobenzene of Pseudomonas sp. strain P51. J. Bacteriol. 173: 6-15

van der Meet JR. Zehnder AJB \& de Vos WM (1991c) Identification of a novel composite transposable element. In 5280 . carrying chlorobenzene dioxygenase genes of Pseudomonas sp. strain P51. J. Bacteriol. 173: 7077-7083

van der Meer JR, de Vos WM. Harayama S \& Zehnder AJB (1992) Molecular mechanisms of genetic adaptation to xenobiotic compounds. Mictobiol. Rev. 56: 677-694

van Loosdrecht MCM. Lykjema J, Norde W, Schraa G \& Zehnder AJB (1987a) Electrophoretic mobility and hydro- 
phobicity as a measure to predict the initial steps of bacterial adhesion. Appl. Environ. Microbiol. 53: 1898-1901

van Loosdrecht MCM, Lyklema J, Norde W, Schra G \& Zehndet AJB (1987b) The role of bacterial cell wall bydrophobicity in adhesion. Appl. Environ. Microbiol. 53: 1893-1897

va Loosdrecht MCM, LykJema J, Norde W Z Zehnder AJB
(1989) Bacterial adbesion: a physicochemical approach. Microb. Eool. 1: 1-15

Zeyer J, Wascerfallen A \& Timmis KN (1985) Microbial mineralization of ring-substituted anilines through an ortho-deavage pathway. Appl. Environ. Microbiol. 50: 447-453 